\title{
Una Aproximación a Honorio Delgado
}

\author{
An approach to Honorio Delgado
}

JosÉ R. EsPINOZA ${ }^{1}$

$\mathfrak{E}$ presente 28 de noviembre se cumplen cincuenta años de la partida de Don Honorio Delgado Espinoza, fundador, primer rector y primer doctor Honoris Causa de nuestra Universidad Peruana Cayetano Heredia. Animado por las conversaciones con el Dr. Roger Guerra García, ex rector, y el Dr. Renato Alarcón, titular de la Cátedra Honorio Delgado, quienes cultivan la memoria histórica de nuestra casa de estudios, he querido ejercer la imaginación de la escritura en base de la lectura de los escritos de don Honorio y de los presentes, sobre aquella mañana decisiva de concepción de la institución que devino eventualmente en la Universidad Peruana Cayetano Heredia.

Este acontecimiento trascendente en la historia de la universidad en el país, seguramente llevó a don Honorio Delgado momentos de profunda reflexión ante las vicisitudes de los hechos que tuvo que vivir en aquel tránsito. En el entendimiento que la historia es siempre una aproximación a un pasado inasible que intentamos devolver de los dominios del

1 Vicerrector académico, UPCH

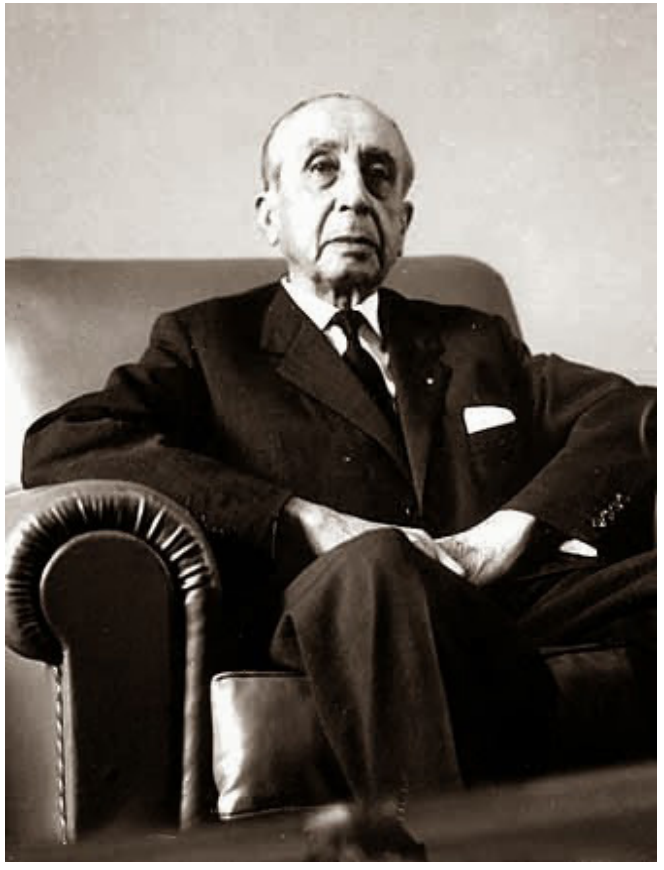

Dr. Honorio Delgado Espinoza (1892-1969)

olvido, pido la consideración favorable por las libertades tomadas en la descripción de los protagonistas y los hechos. 


\section{I}

La mañana de invierno del 25 de julio de 1961 se levantó muy temprano con la incertidumbre de lo que resultaría de la asamblea citada para el mediodía en el Paraninfo de la Facultad de Medicina de San Fernando. Le parecía extraño, que a pesar de la disposición metódica con que acometía sus asuntos, en la que podía contar con un conjunto de acciones premeditadamente decididas para llevarlas a cabo, esta era una de esas situaciones en la que los acontecimientos se sucedían precipitadamente, sin ningún control, y se preguntaba porqué las circunstancias, impredecibles, lo colocaban en una situación extrema en la que había que tomar una última decisión sin la alternativa de asirla por la disuasión o la postergación. Le inquietaba desconocer si los eventos que se avecinaban por suceder resultarían en algo mejor, que sería para bien, encaminados en el ideal de una genuina educación de la juventud, lo había dicho en diversas oportunidades, que le animaba el fin superior de la formación de los estudiantes, pero que estos esfuerzos, los suyos, representaban para los estudiantes descarriados lo tradicional, conservador y que lideraba un sistema de despotismo ilustrado ajeno a las imperiosas necesidades del país. Sentado en la mesa del comedor de su apartamento y con el diario extendido sobre la mesa buscaba alguna noticia de lo que acontecía en San Fernando, "los senadores habian declinado pronunciarse sobre el asunto y han diferido el dictamen al consejo interuniversitario." No les incumbe la educación-se dijo al terminar la nota periodística- y resuélvanlo ustedes, entendió el mensaje, era claro, su propuesta no tenía ninguna opción, la lucha ha sido infructuosa, pensó. De costumbres frugales, solo había bebido una taza de té acompañado de unas galletas ríspidas de avena mientras escuchaba las noticias porque le apremiaba saber si algo más se mencionaba en el noticiero que se emitía por las mañanas en la radio, aún tenía la esperanza secreta que todo se resolvería bajo el imperio de la razón y la concordia. Que, todo no pasaría de un malentendido, un arrebato pasional que daría paso al entendimiento luego de extinguido el fuego de la indignación y la efervescencia política universitaria. Algunos días atrás, Alberto Hurtado y Víctor Alzamora le espetaban respetuosamente que no había otra salida y si estaría de acuerdo con ellos que tenían ya la firme resolución de la renuncia, se habían movilizado con un grupo de profesores que se adherían al movimiento; consideraban que la situación se hacía insostenible, que agotados los esfuerzos por contener los avances del desgobierno en la facultad no quedaba otra alternativa. "Don Honorio, ¿Está Ud. dispuesto a liderar el movimiento, sabe que es una causa justa y persigue un bien superior?" -le había preguntado Alberto Hurtado con esa mezcla de solemnidad y franqueza a la que estaba acostumbrado. Tenía una alta estima y admiración por Alberto, por su dedicación a la investigación y a la formación de los estudiantes. Alberto, cuya educación norteamericana le había inoculado el germen de la acción práctica bajo la certidumbre de su voluntad férrea, estaba inconmoviblemente convencido de que no había otra opción, tenían que irse. Sabía que para Alberto fundar una nueva institución universitaria no escapaba al escenario de las futuras opciones después de la partida. Una universidad de excelencia con su escuela de medicina modelada como una institución de enseñanza e investigación, semejante a aquellas en las que se había formado, pero por sobre todo de investigación al servicio del país, le había escuchado decir en repetidas oportunidades a los médicos más jóvenes. Era quizá una diversidad en el acento, el cultivo de las humanidades es el fundamento de la educación, era el pensamiento que emergía cada vez que escuchaba a Alberto compartir ese anhelo. 
II

"No -dijo Honorio- no estoy seguro si debo hacerlo." Consideró su edad, cumplía en pocos meses setenta años, quería dedicarse a leer, a escribir, a terminar libros suyos, planes que había esbozado mientras completaba la última colección de ensayos que tanta alegría le habían suscitado al escribirlos. Se sentía en su elemento en la reflexión intelectual, absorbido en el manantial de pensamientos de las obras de la última filosofía existencialista alemana, Hartmann y Jaspers -este último como él, médico, psiquiatra, filósofo, con quien sostuvo un enfervorizado encuentro intelectualdedicándoles sendos ensayos filosóficos que exponían su concepción del hombre y de la existencia. Consideraba a Jaspers su par, estaba a su altura, como él, decantado de la praxis psiquiátrica a la filosofía, le tenía muy en cuenta en sus reflexiones sobre el ser del hombre. Sentía que requería poner en el centro de su reflexión al hombre en su condición absoluta insondable y del espíritu dimanaba la trascendencia de su existencia. Tenía que dedicarle al desarrollo de este tema central un tratado que complete su obra lograda sobre la psiquis, que le demandaría la dedicación de años de intensa investigación, reflexión y de escritura. Esa imagen le entusiasmaba, le llenaba de bríos. Había escrito sobre las ultimidades y los arcanos del ser frente a Jaspers, frente a Hartmann. Lo contrastaba con el carácter peruano y la dificultad para profundizar y perseverar, por ello lo raro de las obras originales y de largo aliento de sus compatriotas. No bastaba haberlo señalado, él tendría que demostrarlo una vez más con este tratado que fundamente y unifique el pensamiento filosófico que le desbordaba por dentro en la necesidad de ser, de asir, de estar; le inquietaba el tiempo que le apremiaba para dedicarse a la obra que complete su legado. Lo había dicho a sus amigos, a los cincuenta y cinco años dejaría la práctica médica, se recluiría en el campo de Santa Clara dedicado al "otium cum dignitate" de leer, de escribir, de completar una obra profunda sobre la condición humana, fundamento de su teoría sobre la psiquis del hombre. Esbozó una sonrisa, como si aquel universo de la inteligencia y la cultura a la que había dedicado su vida le confortaba con un hálito de esperanza en la vorágine de los acontecimientos recientes. Pero la demanda del país en estertores políticos consuetudinarios siempre exige más, así asumió el ministerio de educación de un gobierno que atravesaba dificultades políticas. No le podía decir que no a José Luis, compañero de toda la vida desde los primeros años en Arequipa y ahora presidente del Perú con una feroz oposición política que no le permitía ejercer a plenitud el gobierno de la nación. Luego, asumir el decanato de la Facultad de Medicina de San Fernando, sin siquiera pensar que las circunstancias lo colocarían al centro de unos acontecimientos tan externos a su talante. Una vez más la intromisión de la política ideologizada devastaba lo que se avanzaba en educación. En la política, "lo negativo está constituido principal y decisivamente por los herederos del radicalismo intolerante e incomprensivo del siglo pasado y los nuevos fanáticos de la subversión universal que amenazan la plenitud de la cultura por su ceguera para los valores espirituales supremos.» Alberto estaba convencido que el apoyo de Honorio era el fuste necesario para dar el soporte y el momento al movimiento de los docentes de San Fernando, que su estatura contendría el embate subversivo de la politización de la educación médica. Convencido de ello Alberto le respondió: "Don Honorio es una respuesta que no acepto en virtud de nuestra amistad y la valía del Honorio Delgado que todos nosotros conocemos." No lo esperaba ni le fue indiferente; en Alberto veía la objetivación de los principios que había defendido en sus 
asuntos cotidianos y plasmado en sus escritos, pero por sobre todo la autoridad ganada por sus virtudes personales, que como Alberto, se habían dedicado a los fines superiores de la ciencia, la docencia universitaria, la atención al necesitado y la praxis médica. Había escrito sobre algunas cumbres de la humanidad afines; sobre Gracián, jesuita perspicaz de evidente sabiduría y desencanto; de Cajal, un rebelde portento en la ciencia; Paracelso, un grande desconocido; y, Raimondi, dedicado descubridor del Perú. En ellos reconocía la voluntad de vencerse a uno mismo. De la obra construida a pulso por la voluntad del espíritu en el esfuerzo prolongado de elevarse. Por ello, las circunstancias actuales de la Facultad de San Fernando le resultaban inaceptables, que el esfuerzo por la excelencia académica que Alberto, como él, se exige a sí mismo y exigía a los demás, se relegue ante el mandato del promedio que se imponía no por la razón o el conocimiento sino por la fuerza del griterío y de la turbamulta. Alberto estaba en lo correcto, de eso no tenía ninguna duda, pero consideraba que él, un hombre que transita en la senda final de su vida, cómo puede ser el adelantado de un porvenir incierto. No es responsable -ponderó sobre sí mismo- considerarse parte de un futuro al cual uno no pertenece, pero acaso ¿no siempre es así? Seria quizá más útil de compañero de ruta que de adalid del movimiento, pero como decano estaba obligado ponerse al frente de los centenares de profesores de una facultad de la tradición de Hipólito Unanue, de Cayetano Heredia, una responsabilidad histórica que no podía evadir sin mancillar lo que en su consideración era uno de los valores más preciados que había cultivado, la honra que distingue a los mejores, que una vez dañada es imposible de restañar sin dejar huella. "Dr. Hurtado -le dijo- 24 horas para pensarlo y le respondo." Alberto supo que la respuesta de Honorio era ya una afirmación.
III

Se levantó de la mesa para dirigirse a su oficina del Decanato en San Fernando, se despidió de Helene, a quien le había contado de modo general que este día era uno de esos "schwieriger Tag" que se resolvería de algún modo, pero que no sabía cómo. Ella solo le dijo "Gute liebe, auf wiedersehen" al verlo salir con la apostura digna connatural a su persona, en la puerta del edificio de la Avenida Garcilaso de la Vega le esperaba el chofer en la limosina negra que le llevaría por la avenida Grau hasta San Fernando, la mañana era gris, la ciudad se movía en un estado de somnolencia, como atrapada en la suave caída de un velo fúnebre, una garúa que fastidiaba por su su gastada insignificancia que le mojaba el casimir gris que llevaba puesto, una vacua sensación de ausencia parecía llegar a su encuentro en la acera. Subió al auto como si tratase de huir de esta mañana agónica de Lima plomiza. Llego a la oficina y sabía que lo llamarían cuando la convocatoria fuese plena. No había ni siquiera culminado de ordenarse cuando tocaron la puerta. Era Alberto que le dijo, "Don Honorio, el paraninfo está colmado de profesores, la convocatoria a la Asamblea de los Docentes de la Facultad de Medicina de San Fernando había sido un éxito.", "Un momento Alberto, por favor" -le dijo cerrando suavemente la puerta. Volvía sobre sus pasos y pensaba que llevaría a un hombre dedicado una vida a la práctica médica y la reflexión intelectual a sus casi 70 años a iniciar la aventura incierta del cisma de una institución en la que había pasado su vida entera. Qué decisión difícil, pensó mientras recordaba que había pasado su vida en la exigencia interior de alcanzar los más altos niveles de conducta intelectual y moral en la vida pública, la docencia universitaria y la práctica médica en San Fernando. Absorto en estos pensamientos, levantó el teléfono y llamo a casa, "Liebe Helene, das fünf, bitte", Helene posó el auricular sobre 
la mesa, se sentó al piano y toco los primeros compases alegres del concierto para piano "El Emperador" de Beethoven. Honorio cerró los ojos por un momento y en silencio pensó en Helene, sentada al piano, deslizando sus finos dedos sobre el teclado. Ella que lo dejó todo en Alemania para venir con él al Perú, aquí se casaron y Herminio Valdizán fue su padrino. Siempre sentía que su ser interior se extendía con Helene y lo lanzaba de vuelta al mundo, sentía que la vida con ella era un viaje no exento de belleza y alegría. "Danke meine liebe" - dijo y colgó el teléfono al sentir que ella se había detenido. Se le agolpó a la memoria la llegada a Lima para iniciar sus estudios de medicina, instructor de anatomía siendo estudiante, la cerrada defensa por la enseñanza de la fisiología, luego semiología, patología, el psicoanálisis y el devenir en psiquiatra. Aquí había sentido la satisfacción del ejercicio de la docencia, del estudio y de la creación, aquí había soñado con una vida dedicada a la medicina y a la cultura, aquí en San Fernando lo había logrado. Pero, también aquí lo fustigaron sin entender porque lo hacían, lo señalaban como un ser anacrónico adverso a los vientos nuevos de la reforma, un aristócrata supérstite del siglo pasado. No te opongas al agravio, pensó. Seguidamente pensó que al frente de los centenares de docentes decididos a dejarlo todo atrás no había otra opción que dejar que los acontecimientos se decanten solos. Se levantó con un impulso instantáneo de vitalidad y encontró a Alberto esperándolo en la puerta. "Vamos" -le dijo y caminaron en silencio por el pasadizo que llevaba al paraninfo. "Quiera Dios -se dijo poco antes de llegar a la puertaque la voluntad de su espíritu guíe las decisiones de esta Asamblea" y al cruzar el vano escuchó el ensordecedor aplauso que retumbaba el paraninfo. Alberto -pensó- solo don Honorio puede suscitar este aunamiento de voluntades. Alguien le alcanzó un papel, le dijeron que era un manifiesto escrito por Víctor Alzamora, lo leyó rápidamente mientras se desenvolvía la vorágine inicial de la asamblea en la que se sucedían los oradores uno más apasionado que otros, volvió a leer el documento de Víctor. "Que se lea el manifiesto" -exigió a los que lo acompañaban en la alta mesa de la Asamblea mientras le alcanzaba el papel al relator de la asamblea. Cuando se inició la lectura un silencio unánime se apodero del paraninfo, lo que antes era un alborotada sucesión de exclamaciones y reclamos, de pronto se tornó en atención expectante y luego en vítor general. "Alea jacta est" -se dijo a sí mismo- y tuvo certeza que la suerte estaba echada, que en este acto oficial como decano se despedía de San Fernando y lo que se concebía en aquel momento era un sueño propiciado por una magnifica concertación de voluntades.

Lima, agosto-septiembre del 2019. 